ISSN 2073-4360

Editorial

www.mdpi.com/journal/polymers

\title{
Open Access Makes an Impact
}

\author{
Alexander Böker \\ Editor-in-Chief of Polymers, DWI an der RWTH e.V., Lehrstuhl für Makromolekulare Materialien und \\ Oberflächen, RWTH Aachen University, D-52056 Aachen, Germany; \\ E-Mail: boker@mdpi.com; Tel.: +49-241-80-23304; Fax: +49-241-80-23317
}

Received: 2 July 2013 / Accepted: 2 July 2013 / Published: 5 July 2013

Polymers published its first issue in December 2009. At that time, the editorial board and publisher were determined to lead the journal to become another MDPI success story, proving that open access publishing and high quality publications, ensured by a rigorous peer-review procedure, followed by fast publication of accepted manuscripts can be achieved. Three and a half years later, after more than 153,000 article downloads in 2012, the journal received its first impact factor (2012 JCR IF: 1.687). Today, Polymers is proud to be the number one open access journal in the category of "Polymer Science". In order to achieve this, we relied on an editorial board with well-known members from the polymer community, a professional staff and a vision that there is room alongside the established "high impact" journals for publishing science. Recently, the editor in chief of Science, Bruce Alberts, wrote an editorial [1] in favor of the San Francisco Declaration on Research Assessment (DORA), which states that the impact factor must not be used as "a surrogate measure of the quality of individual research articles [2]". Even though the impact factor certainly is so far the best available measure of the quality of a journal and its impact on the scientific community, when it comes to the single manuscripts published, "there is still no other way to evaluate the quality of scientific papers, but to read them [3]". Therefore, Polymers celebrates its first impact factor with an appropriate critical distance towards bibliometric data and feels encouraged to continue on the chosen path. With this in mind, I encourage you, our readers, to continuously evaluate the scientific quality of the articles published in Polymers by reading, discussing and citing them.

\section{References}

1. Alberts, B. Impact factor distortions. Science 2013, 340, 787.

2. DORA. Available online: www.ascb.org/SFdeclaration.html (accessed on 2 July 2013). 
3. Decker, O.; Beute, M.; Brähler, E. Deep impact-Evaluation in the sciences. Sozial und Präventivmedizin 2004, 49, 10-14.

(C) 2013 by the authors; licensee MDPI, Basel, Switzerland. This article is an open-access article distributed under the terms and conditions of the Creative Commons Attribution license (http://creativecommons.org/licenses/by/3.0/). 